\title{
Iot(Internet of Things) Based Smart Device Network to Monitor and Control Urban Air Pollution
}

\author{
SOURAV MUKHERJEE
}

\begin{abstract}
IoT(internet of things) are smart electronic devices connected through the internet. As time passes there are more IoT devices around us and the number can climb to an astronomical amount of 41.6 billion by 2025 as per reports [1]. The paper deals in modelling of an innovative IoT based system to cope up with urban air pollution. The system aims to act as an innovative 'Quality Indicator and Preservation System for Air'(QIPSA). 'QIPSA' is a system with both hardware and software components. The hardware part consists of a large number of IoT electronic devices embedded near the roadside lamp posts to collect data in order to calculate local AQI. The software part involves in showing real-time pollutant \& AQI data and involving in decision making to stabilise AQI. It can be used by regulating authorities to manage traffic efficiently such that the AQI(Air Quality Index) gets as low as possible. Civilians can use the system to decide their preferred route for daily works considering the AQI . The purpose of the system is to create a cost-effective hardware sensor network which provides real-time data and can be observed through a mobile application.

Index Terms: Internet of things, smart devices, air pollution, IoT monitoring, mobile application.
\end{abstract}

\section{INTRODUCTION}

Air pollution is one of the biggest threats to the human civilisation in current scenario [2]. India, the second most populated country on earth is suffering the most. The capital city Delhi, infamously called "gas chamber" was announced by the World Health Organisation(WHO) as the most polluted city in the world [3,4]. Chart 1 shows that transportation is the major contributor to the air pollution in Delhi [5].

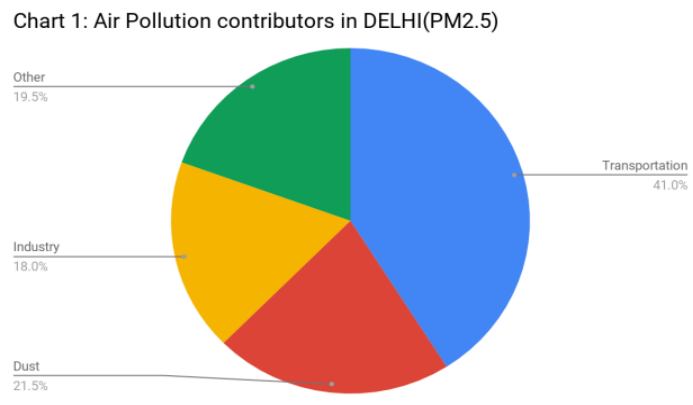

Manuscript published on November 30, 2019.

* Correspondence Author

Sourav Mukherjee, CEO, Quaxar Technologies Private Limited

(C) The Authors. Published by Blue Eyes Intelligence Engineering and Sciences Publication (BEIESP). This is an open access article under the CCBY-NC-ND license http://creativecommons.org/licenses/by-nc-nd/4.0/
Several steps have been taken(Odd-even scheme being one famous effort) by the government to tackle the issue and more efforts are to be made. Our solution, QIPSA can be a handy tool for the government to monitor and preserve air quality managing the traffic through data driven decisions.

\section{SYSTEM ARCHITECTURE}

The system will have a network of hardware that sends sensor data to cloud storage, determines AQI and shows graphical data in real time on the mobile application $[6,7$, 8]. QIPSA can broadly be divided into two parts- hardware and software.

\section{A. Hardware}

Roadside lamp posts are ideal to place the hardware. It solves two problems, one is the abundance of power source and the other is to acquire data from road areas. The power source from lamp post can be converted to $3.3 \mathrm{v}$ dc supply to feed the WiFi module(here ESP32). Sensors are connected with the module to obtain data from the location. The data are uploaded to cloud server. The block diagram 1 explains the system structure.

\section{B. Software}

Data from cloud can be fetched and shown on the application. There will be two variants of the application. One for the civilian and the other one for traffic regulating authority. AQI(Air quality index), a numerical number can easily be calculated using the sensor data from the mathematical formula shown in the report about National Air Quality Index by Central Pollution Control Board, Government of India [9].

Table 1: AQI and breakpoint concentration of pollutants [10].

\begin{tabular}{|c|c|c|c|c|c|c|c|c|c|}
\hline $\mathrm{AOI}$ & $\begin{array}{l}\text { Colour } \\
\text { Code }\end{array}$ & $\begin{array}{l}\text { PM 2.5 } \\
\left(\mu g / m^{\circ}\right)\end{array}$ & $\begin{array}{l}\text { PM 10 } \\
\left(\mu g / m^{5}\right)\end{array}$ & $\begin{array}{l}\infty \\
\left(m g / m^{5}\right)\end{array}$ & $\begin{array}{l}\mathrm{NO}_{2} \\
\left(\mu \mathrm{g} / \mathrm{m}^{3}\right)\end{array}$ & $\begin{array}{l}\mathrm{SO}_{2} \\
\left(\mu \mathrm{g} / \mathrm{m}^{3}\right)\end{array}$ & $\begin{array}{l}o_{5} \\
\left(\mu \mathrm{g} / \mathrm{m}^{5}\right)\end{array}$ & $\begin{array}{l}\mathrm{NH}_{3} \\
\left(\mu_{\mathrm{g}} / \mathrm{w}^{3}\right)\end{array}$ & $\begin{array}{l}P_{0} \\
\left(\mu g / m^{5}\right)\end{array}$ \\
\hline $\begin{array}{l}\text { Good } \\
(0.50)\end{array}$ & Light geesen & 0.30 & 10.50 & $0-1$ & 0.40 & 0.40 & 0.50 & 0.200 & 0.05 \\
\hline $\begin{array}{l}\text { Surstsciary } \\
(51-100)\end{array}$ & Dexp geen & $31-60$ & $51-100$ & $1.1-2.0$ & $41-80$ & $41-80$ & 51- 100 & $201-4000$ & $0.5-1$ \\
\hline $\begin{array}{l}\text { Moderandely } \\
\text { pollunod } \\
(101-200\rangle)\end{array}$ & Pirik & $61-90$ & ${ }_{0}^{101-25}$ & 21-10 & $81-190$ & $81-390$ & $101-168$ & $401-8000$ & 1.12 .20 \\
\hline $\begin{array}{l}\text { Porr } \\
\text { (201-300) }\end{array}$ & Orange & $91-120$ & ${ }_{0}^{251-35}$ & 10-17 & $181-280$ & $301-2000$ & 1092008 & $2011-1200$ & $2.1-3.0$ \\
\hline $\begin{array}{l}\text { Very porr } \\
(301-400)\end{array}$ & Red & $0_{0}^{121-25}$ & $3_{0}^{351-43}$ & 17.34 & $281-4000$ & $801-1000$ & 209749 & $1201-1000$ & 3.1.3.5 \\
\hline $\begin{array}{l}\text { Severe } \\
\text { (>450) }\end{array}$ & $\begin{array}{l}\text { Dewp Red } \\
\text { (Maroxn) }\end{array}$ & $250+$ & $430+$ & $34+$ & $400+$ & $1600+$ & $789+$ & $18000+$ & $3.5+$ \\
\hline
\end{tabular}




\section{Iot(Internet of Things) Based Smart Device Network to Monitor and Control Urban Air Pollution}

As per CPCB's report calculation of AQI is broadly a two way process-(i) Calculating sub-air quality indices of the individual pollutants, (ii) Calculating the overall air quality index.

(i) Calculating sub-air quality indices:

Sub air quality index $\square_{\square}$ for a pollutant concentration, $\square_{\square}$ can be calculated from the equation:

$$
\square_{\square} \quad=\left[\left\{\left(\square_{\square \square}-\square_{\square \square}\right) /\left(\square_{\square \square}-\square_{\square \square}\right)\right\} *\left(\square_{\square}-\square_{\square \square}\right)\right]+\square_{\square \square}
$$

$\square_{\square \square}$ is the breakpoint concentration greater or equal to given concentration.

$\square$ is the breakpoint concentration smaller or equal to given concentration.

$\square_{\square \square}=$ AQI value corresponding to $\square_{\square \square}$

$\square_{\square \square}=$ AQI value corresponding to $\square_{\square \square}$

(ii) Calculating overall AQI:

Overall AQI $=\operatorname{Max}\left(\square_{\square}\right)[\mathrm{p}=1,2,3, \ldots \mathrm{n}$; denotes $\mathrm{n}$ pollutants]

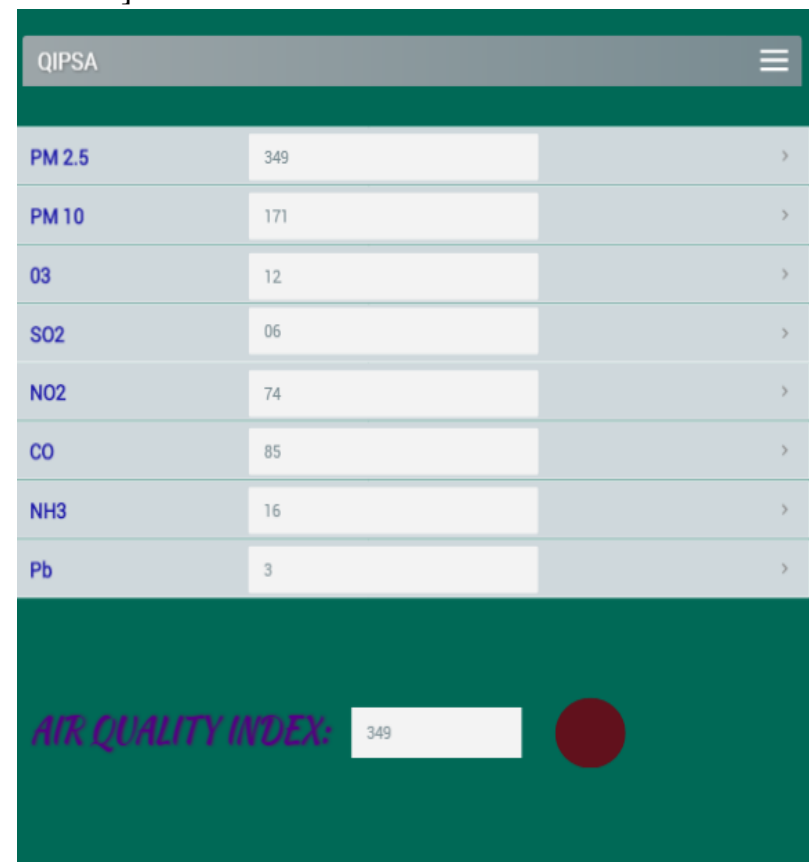

Picture 1: Calculated AQI on the application

\section{SYSTEM OPERATIONS}

Two variants of the application will be having different objectives. The civilian version is aimed to help common people plan their daily routines, government version of the app is mainly focused to take necessary actions in the traffic to control pollution.

(i) Civilian use version:

The app dedicated for civilians should have the AQI information of nearby areas so that they can have an idea of the air quality nearby [11]. People with higher sensitivity to poor air quality can avoid areas with hazardous AQI. Morning joggers who roam to breathe fresh air can have a clarity on their jogging routes. Overall the system would help the common people to be better equipped to deal with air pollution.

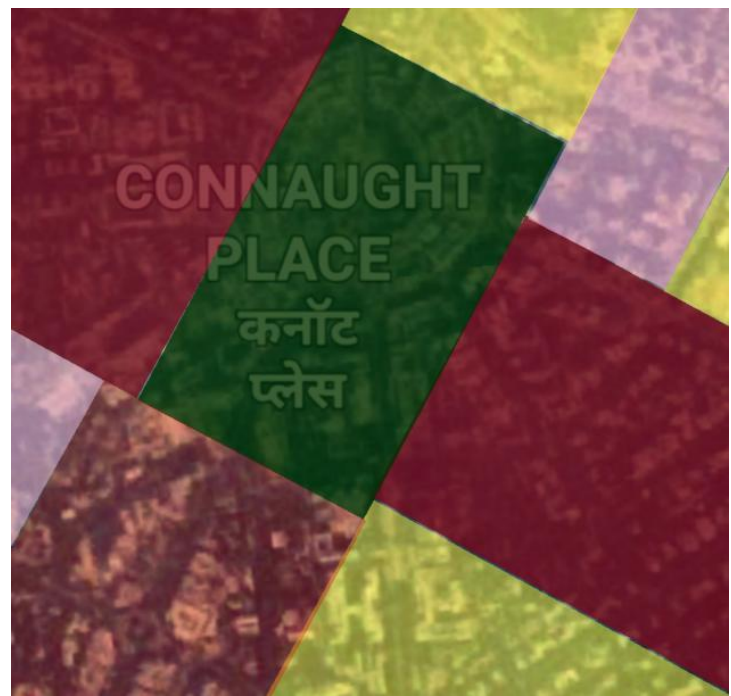

Picture 2: Colour indication in map

(ii) Government use version:

Traffic regulating authorities can control the traffic in a way to stabilise the air pollution. With availability of enough data, the application can show routes with different AQI levels. The concerned traffic regulating authority can cut the operations in the routes with severe AQI for some period of time. Transportation is one of the key causes of air pollution and the efficient operation of the process should decrease the pollutant concentration in a particular area resulting reduced AQI in that area.

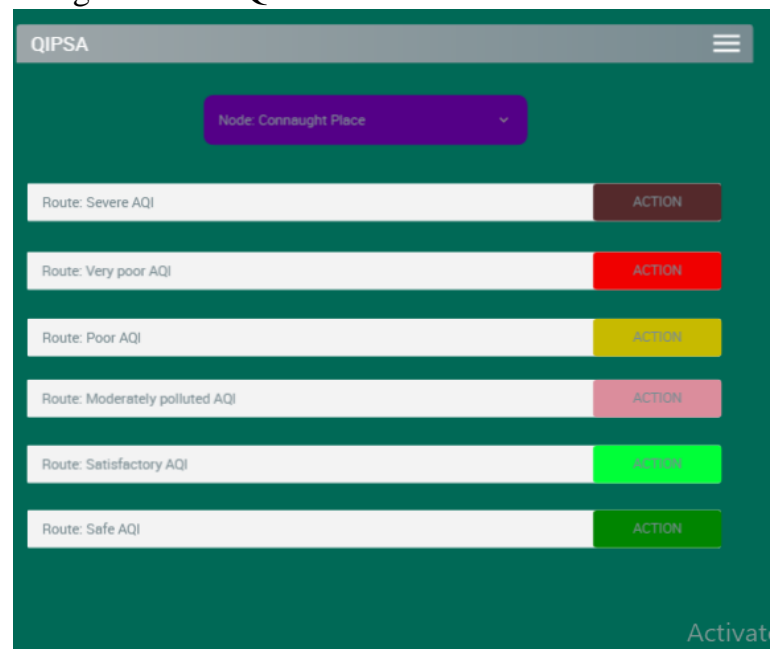

Picture 3: App interface for traffic regulating authorities

\section{IMPLEMENTATION}

As the situation is getting more severe, the government isn't hesitant to take stern steps, Odd-Even scheme being a prime example. Our survey on daily delhi commuters show the civic awareness and support to tackle air pollution. Bar 1 shows some insightful data. 


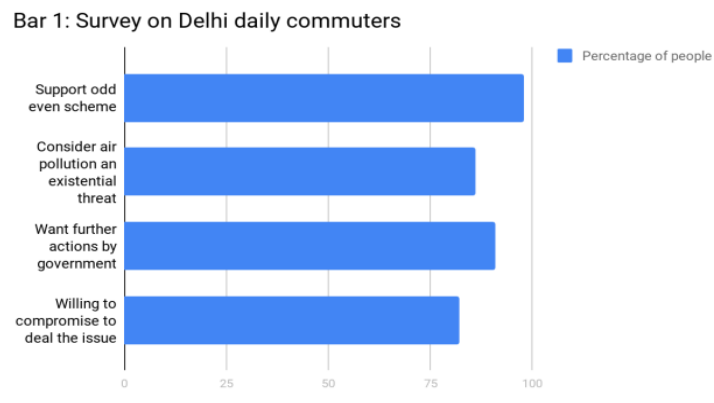

\section{AUTHOR PROFILE}

Sourav Mukherjee is currently working as the CEO of Quaxar Technologies Private Limited. He is one of the co-founders and director of the company. He got his Bachelor of Technology(B.Tech) in Electronics and Communication Engineering from Techno India University, Kolkata. A gold medalist for his outstanding achievement in academic performance and an innovator. Sourav holds multiple national and international recognition as an innovator. His research interests are Internet of Things(IoT) application, embedded systems, analogue circuit designing, information theory and designing of communication systems. He aims to convert technical innovations to marketable socially impactful products in order to add value in the society.

\section{CONCLUSION}

It is high time to not only gather AQI data but to use it most efficiently by harnessing the latest technologies. The implementation of the system relies on government's effort and public cooperation. The survey of Delhi shows public inclination to support government steps to mitigate air pollution. If implemented properly, the system can be an efficient alternative of the odd-even scheme. Moreover, an extension of the system can also be implemented in google map's traffic routes where people can drive through the route with the best AQI(Just like they get to know the route with least traffic).

\section{REFERENCES}

1. "41.6 billion IoT devices will be generating 79.4 zettabytes of data in 2025 - Help Net Security", Help Net Security, 2019. [Online]. Available: https://www.helpnetsecurity.com/2019/06/21/connected-iot-devicesforecast/. [Accessed: 18- Nov- 2019].

2. "Global catastrophic risk", En.wikipedia.org, 2019. [Online]. Available: https://en.wikipedia.org/wiki/Global_catastrophic_risk. [Accessed: 05Nov- 2019].

3. "Better not be in Delhi, it's like 'gas chamber': Supreme Court", The Economic Times, 2019. [Online]. Available: https://economictimes.indiatimes.com/news/politics-and-nation/betternot-be-in-delhi-its-like-gas-chamber-supremecourt/articleshow/67590551.cms?from=mdr. [Accessed: 10- Nov- 2019].

4. "Delhi is world's most polluted city: WHO study- Business News", Businesstoday.in, 2019. [Online]. Available: https://www.businesstoday.in/current/economy-politics/who-study-delhimost-polluted-city/story/205985.html. [Accessed: 01- Feb- 2019].

5. "Air pollution in Delhi", En.wikipedia.org, 2019. [Online]. Available: https://en.wikipedia.org/wiki/Air_pollution_in_Delhi. [Accessed: 18Nov- 2019].

6. N. Zakaria, Z. Zainal, N. Harum, L. Chen, N. Saleh and F. Azni, "Wireless Internet of Things-Based Air Quality Device for Smart Pollution Monitoring", International Journal of Advanced Computer Science and Applications, vol. 9, no. 11, 2018. Available: 10.14569/ijacsa.2018.091110.

7. H. Hawari, A. Zainal and M. Ahmad, "Development of real time internet of things (IoT) based air quality monitoring system", Indonesian Journal of Electrical Engineering and Computer Science, vol. 13, no. 3, p. 1039, 2019. Available: 10.11591/ijeecs.v13.i3.pp1039-1047.

8. S. Dhingra, R. Madda, A. Gandomi, R. Patan and M. Daneshmand, "Internet of Things Mobile-Air Pollution Monitoring System (IoTMobair)", IEEE Internet of Things Journal, vol. 6, no. 3, pp. 5577-5584, 2019. Available: 10.1109/jiot.2019.2903821.

9. Central Pollution Control Board (Ministry of Environment, Forests \& Climate Change), "NATIONAL AIR QUALITY INDEX", PR Division on behalf of Dr. A.B. Akolkar, Member Secretary, CPCB, Delhi-110032, 2014, page-27.

10. Central Pollution Control Board (Ministry of Environment, Forests \& Climate Change), "NATIONAL AIR QUALITY INDEX", PR Division on behalf of Dr. A.B. Akolkar, Member Secretary, CPCB, Delhi-110032, 2014, page-26.

11. H. Zahmatkesh, M. Saber and M. Malekpour, "A New Method for Urban Travel Route Planning Based on Air Pollution Sensor Data", Current World Environment, vol. 10, no. -1, pp. 699-704, 2015. Available: 10.12944/cwe.10.special-issue1.83. 